\section{Remote Control of a Scanning Electron Microsocpe Using Asynchronous Transfer Mode}

Nancy R. Smith, Don Pardoe, Corinne Pelote, Mark Honer, and Christopher L. Morgan: California State University, Hayward, CA

California State University, Hayward has successfully demonstrated remote control of a scanning electron microscope (SEM) using Asynchronous Transfer Mode (ATM). The development of digital imaging technology has lead to exploration and testing of networking strategies for sharing scientific instrumentation. ${ }^{1,2,3}$ The concept of shared instrumentation is appealing to both academia and private enterprise. Networking access presents the opportunity to teach scanning electron microscopy to a large number of students using multiple desktop computers. ${ }^{4}$ Video images can also be projected onto large screens in classrooms or as a distant learning resource. Remote shared access to scientific equipment provides certain advantages such as access to a wider variety of resources, direct interaction without hazard to people or equipment, ability to combine resources into larger virtual instruments, rapid access to available resources, and pooling of knowledge by a larger community. The advent of high speed networks such as ATM offers the possibility of integrated solutions to communication and control.

ATM provides a high speed Virtual Circuit (VC) switched environment. Connection set-up of a VC may be arranged either as a Permanent Virtual Circuit (PVC) or as a dynamic Switched Virtual Circuit (SVC). Data passed to a $V C$ is segmented into 53 octet quantities called cells ( 5 octets of an ATM header and 48 octets of data). The small fixed-length packet size provides a basis for high speed switching and transport of video, data and audio. Multiplexing equipment allows various combinations of digital
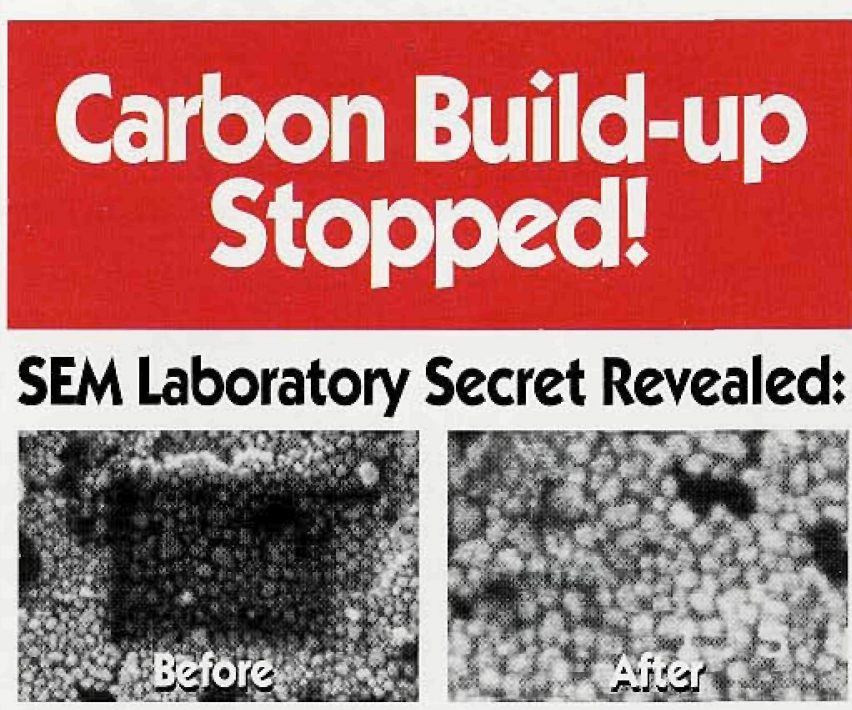

SEM manufacturers won't admit it, but most SEMs are subject to contamination build-up-even dry pumped systems. To stop hydrocarbon condensation, smart SEM users rely on the XEI Scientific SEM-CLEAN ${ }^{\top M}$ system.

Result: Outstanding pictures at low $\mathrm{kV}$ and high resolution and no oil on EDS X-ray detector windows. The Nitrogen purge of the inexpensive SEM-CLEAN system cleans your electron microscope while you're away.

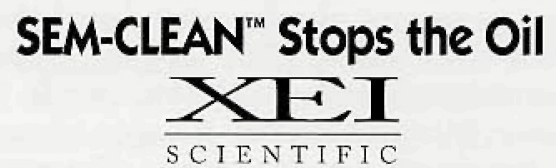

3124 Wessex Way, Redwood City, CA 94061 415-369-0133 • Fax 415-363-1659 information streams to be mixed into one connection for transmission over the ATM network.

An ATM network attaches the Hayward campus to an ATM switch that also serves other CSU campuses, including San Francisco, San Jose, and Fullerton. This network is a mixture of OC3 (155 Mbps) and DS3 (45 Mbps) transmission lines. The resulting network offers multiplexed, high speed connections at DS3 speeds. The connection to Hayward is actually carried by 0012 (622.08 Mbps) on an optical fiber which is capable of much higher capacity for future expansion. Currently, only Permanent Virtual Circuit (PVC) service is available. This service provides a set of dedicated links to the CSU system. Presently, the network is controlled by individually configuring each node to create connections among links. This is done by one CSU network management person, operating via telnet sessions to each switch. This individual must carefully manage the entire CSU network to conform to carrier bandwidth limitations on each link.

The microscope used in this study is a Philips XL-40 SEM. It is equipped with an IXRF X-ray microanalyzer and digital imaging system. The SEM is controlled by a $486 \mathrm{PC}$ and runs Windows-based software to control the microscope over a SCSI interface. Currently, as many as 5 samples can be loaded at the same time. Another specimen stage is being designed so that as many as 16 samples can be loaded. The user interface of the SEM consists of a 17 inch monitor to display the image while graphic control functions are overlaid on top of the image. The video signal can also be displayed separately on larger monitors in classrooms. Microscope operations, including movement of the motorized stage, are accessed using Microsoft Windows. A set of programs in the Windows environment allows users to control the position of the samples and other parameters such as magnification, accelerating voltage changes, spot size changes, brightness and contrast, etc. The few functions requiring local, manual access to the microscope are sample insertion, tilting of the stage and Z-axis control. The attached X-ray microanalyzer is separately controlled by a Pentium 90 . Video output and data transfer from the SEM is available through several types of network access including the cmpus Ethernet backbone, closed circuit video on campus, community cable TV, Integrated Services Digital Networking (ISDN), and ATM.

The SEM was acquired through a National Science Foundation/Improvement in Laboratory Instrumentation award. The proposal was submitted by Richard Tullis and Nancy Smith of the Department of Biological Sciences and Nancy Fegan of the Department of Geological Sciences. The grant entitled "Interactive Curriculum Using a Scanning Electron Microscope", consisted of two phases. Phase I is to bring remote control of the SEM into classrooms on the Hayward campus. Phase II is to remotely control the microscope from other CSU campuses. Phase I has been successfully demonstrated from classrooms within the building housing the SEM and from the distant learning classroom located approximately one-half mile away. So far, demonstrations have been conducted operating the SEM on the Hayward campus from the San Jose campus. Control of the instrument is transmitted over a data channel and the visual output is carried over a $10 \mathrm{Mbps}$ compressed video channel. Both types of signals are carried over the same ATM connection. Attempts to control the SEM from San Francisco are planned.

The successful demonstration of remote control of the SEM using ATM used the following configurations. The PC at the San Jose site was equipped with PC Anywhere software to control the Windows software on the SEM. The video was carried over the CSU CaIREN ATM between the campuses and control of the SEM was over the CSU T1-based Intercampus connection.

The deployment of the SEM is a first step in providing students in the CSU system with remote interactive shared access to scientific instrumentation. Current instrumentation interfaces open the way to remote sharing of expensive equipment. Support in the form of curriculum development, ATM network access, and matching funds for the microscope have been provided by the Distributed Learning Resources (DLR) project funded by Pacific Bell and a DELTAVDLR grant from the CSU System. Further information can be obtained from our web page. The URL is http://www.mcs.csuhayward.edu/sem/.

\footnotetext{
T.A. Dodson, et al., Proc. 53rd. Meeting of MSA (1995) 16

M.H. Ellisman Proc. 53rd Meeting of MSA (1995) 66

N.J. Zaluzec, Proc. 52nd Meeting of MSA (1994) 390.

S. Chumbley, et al, (1995) Micro Res \& Tech. 32:330.
} 


\section{MaXim 2000}

\section{Scanning Electron Microscopes}

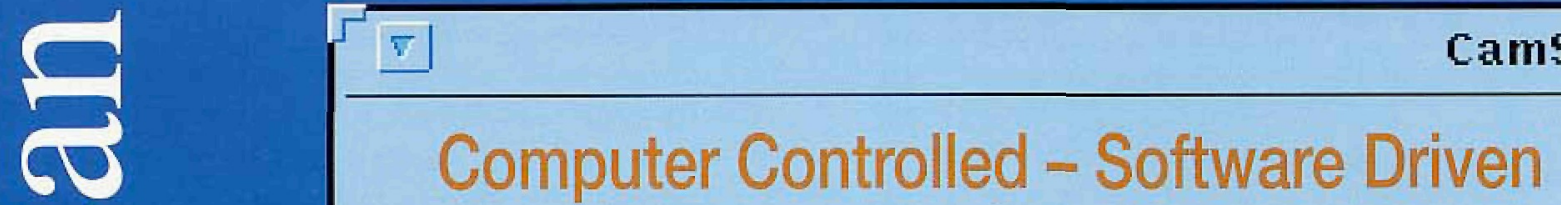

The new approach to high performance Analytical Microscopy offering technical sophistication to suit either the experienced or occasional user.
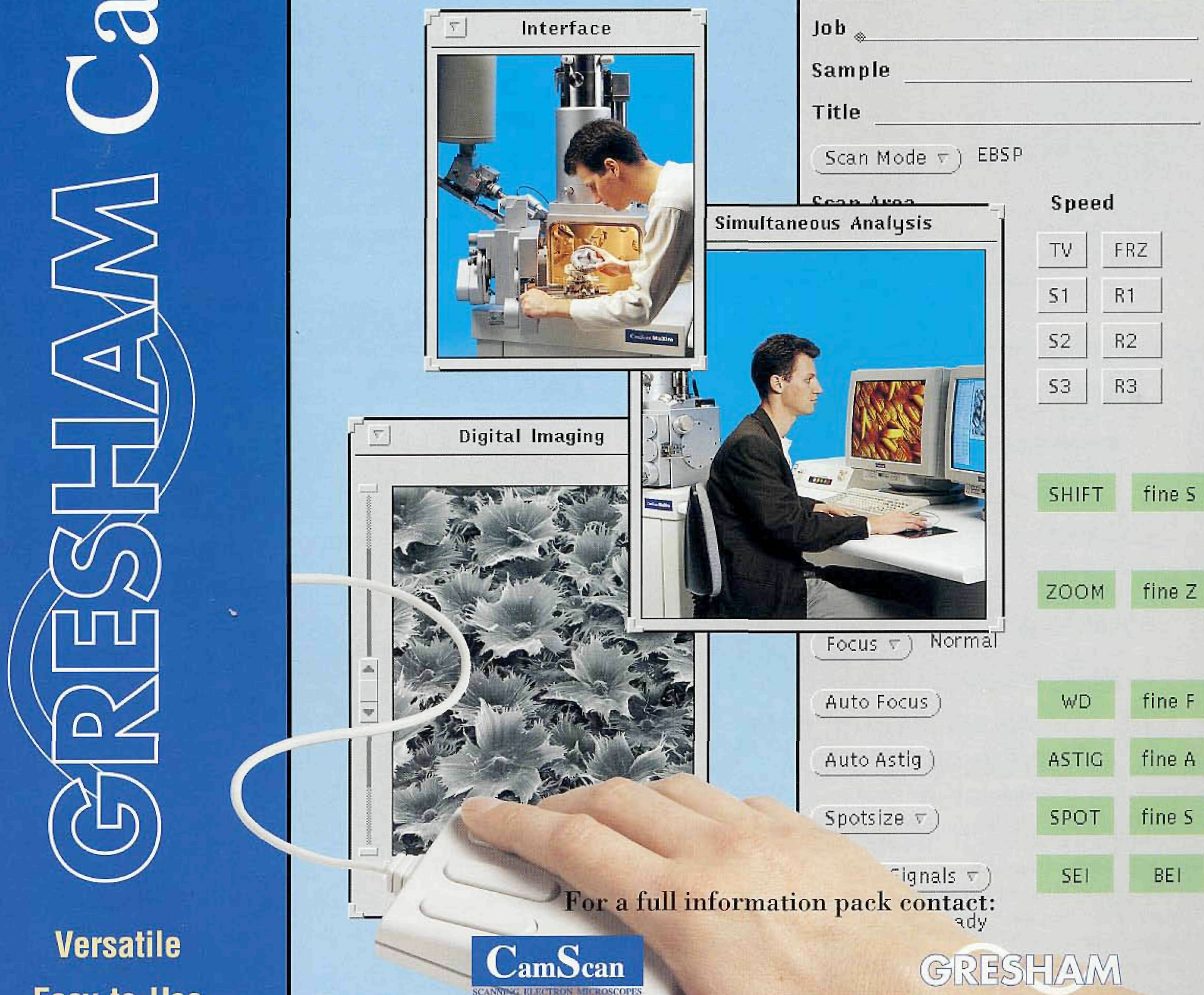

Easy-to-Use

Uneompromised Quality

CamScan USA Inc.

508 Thomson Park Drive, Cranberry Township, PA 16066-6425 USA. Tel: (412) 7727433 Fax: (412) 7727434

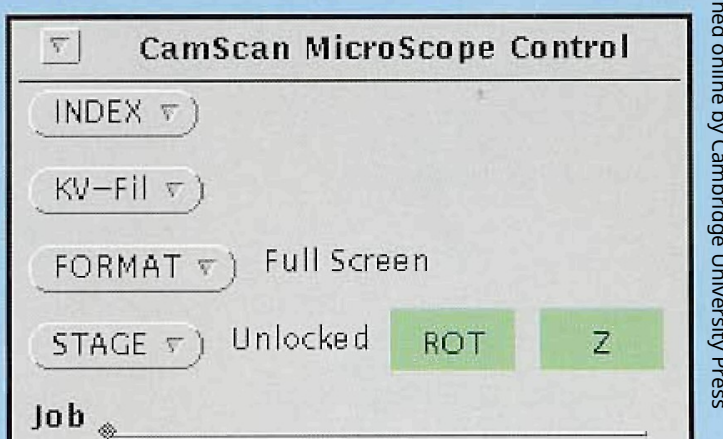

Speed

\begin{tabular}{|l|l|}
\hline TW & FRZ \\
\cline { 1 - 1 } 51 & R1 \\
\hline 52 & $R 2$ \\
\hline 53 & $R 3$ \\
\hline
\end{tabular}

SHIFT fine 5

zoom fine $z$

ASTIG fine Aे

SPOT fine 5

SEI $\quad$ BEI

\section{Gresham-CamScan}

CamScan House, Pembroke Avenue,

Waterbeach, Cambridge CB5 9PY, UK. Tel: $+44(0) 1223861066$ Fax: +44 (0) 1223861077 


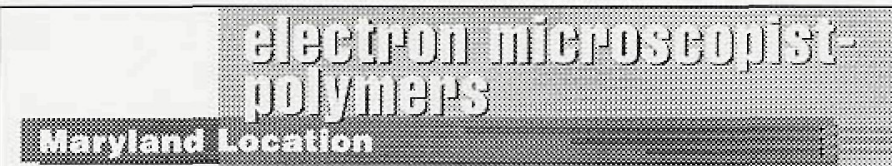

W.L. Gore \& Associates, Inc., named as one of "The 100 Best Companies to Work for in America" and recognized as a progressive, high technology company, offers unique opportunities for career growth. We are a global leader in fluoropolymer technology and have diversified products in electronic, industrial, medical and GORE-TEX fabrics applications. W.L. Gore is a privately held corporation with technology and manufacturing facilities clustered in Delaware, Maryland, Europe and Japan.

There is an immediate opportunity for an Electron Microscopist at one of our Maryland facilities.

\section{Responsibilities:}

- Build a state-of-the-art analytical electron-optics facility

- Develop methods for analytical

characterization of polymers

- Develop methods for high resolution imaging of polymers using both

SEM and TEM

- Pull together a global team tocused on electron-optics characterization

- Teach analytical electron-optic

characterization to other Gore associates

Please send or fax resume to:

\section{W.L. GORE \&}

\section{ASSOCIATES, INC.}

Attn: $\mathrm{CH} 1738$

P.O. Box 9206

Newark, DE 19714-9206

Fax: (302) 292-4156

Equal Opportunity Employer

\section{Requirements include:}

- Advanced degree in sciencel engineering with a strong materialst polymer background

- Minimum of five years extensive hands-on industrial experience on SEMs and EDSMDS

- Extensive experience with sample preparation techniques and imaging of synthetic polymers

- Demonstrated experience with quantitative image analysis

- Hands-on experience with TEMs

- Experience with statistical design of experiments

- Excellent interpersonal skills with proven record of working in a team environment

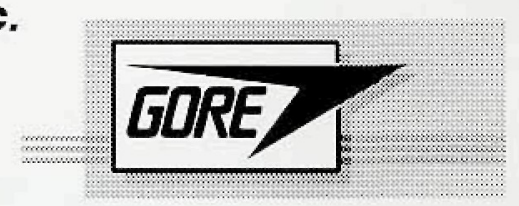

\section{Point \& Click}

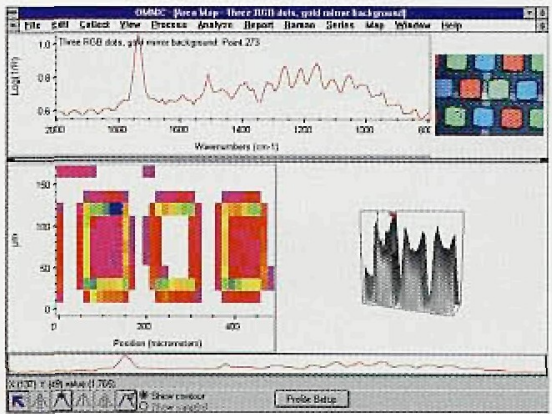

\section{for automated spectral data collection and display!}

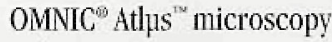
software gives you superior control of your FT-IR microscope. Its Windows ${ }^{\mathrm{s}}$ compatible interface allows you to interact directly with a live video image of your sample, to perform automated data collection and to extract specific information using line, area or 3D maps.
Put the power of OMNIC Athus to work in your lab! Contact Nicolet today!

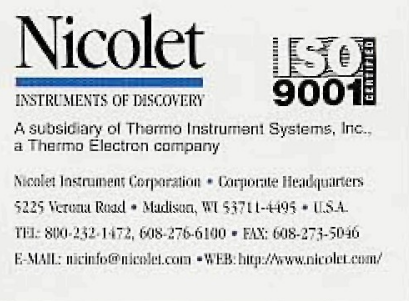

\section{Shot A Query Into-The Net}

I shot a query into the net.

I haven't got an answer yet,

But seven people gave me hell

And said I ought to learn to spell;

A posted message called me rotten

For ignoring mail I'd never gotten;

An angry message asked me, Please

Don't send such drivel overseas;

A lawyer sent me private maid

And swore he'd slap my butt in jait.

I'd mentioned Un' $x$ in my gem

And faited to add the $T$ and $M$;

one netter thought it was a hoax;

"Hereafter, post to net dot jokess";

Another called my grammar vite

And criticized my writing style.

Each day I scan each subject line

In hopes the topic will be mine;

I shot a query into the net.

And havent got an answer yet.

Compliments of Ron Anderson, IBM Corporation - as " received from an unknown source.

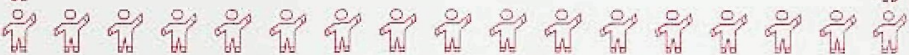

\section{COST PAPACINE IDM MAANIETIC SHUIIDING!}

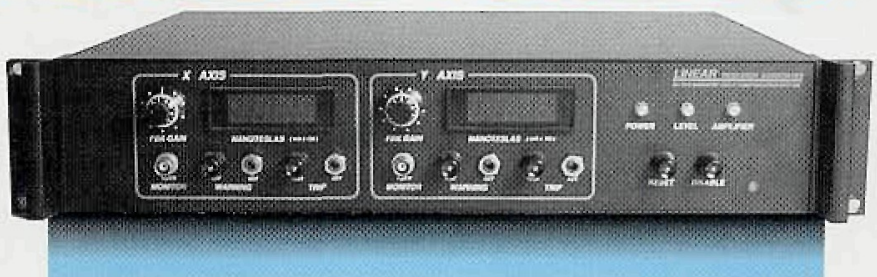

LINEAR RESEARCH ASSOCIATES' wideband EMFC-AC electronic active-shielding systems dramatically reduce magnetic fields from a.c. power wiring, ground loops, transformers and related sources. EMFC-QDC extended-range models effectively suppress low-frequency magnetic disturbances caused by trains, subways, elevators and MRI scanners.

EMFC systems are recommended, cost-effective protection for sensitive FEG and PEELS apparatus.

All Linear Research EMFC equipment features state-of-the-art engineeringtt and is U.S.-manufactured to exacting standards. Superior performance and reliability are guaranteed!

Call of fax LRA for complete EMFC-series information. We will also gladly assist with any questions you may have regarding site survey, engineering or EMF issues.

\section{LINEAR RESEARCH ASSOCIATES}

5244 Perry City Road - Trumansburg, NY 14886

Phone (607) $387-3411$ • Fax (607) 387-7806

t† U.S. Patents $5,465,012 ; 5,469,058$ 

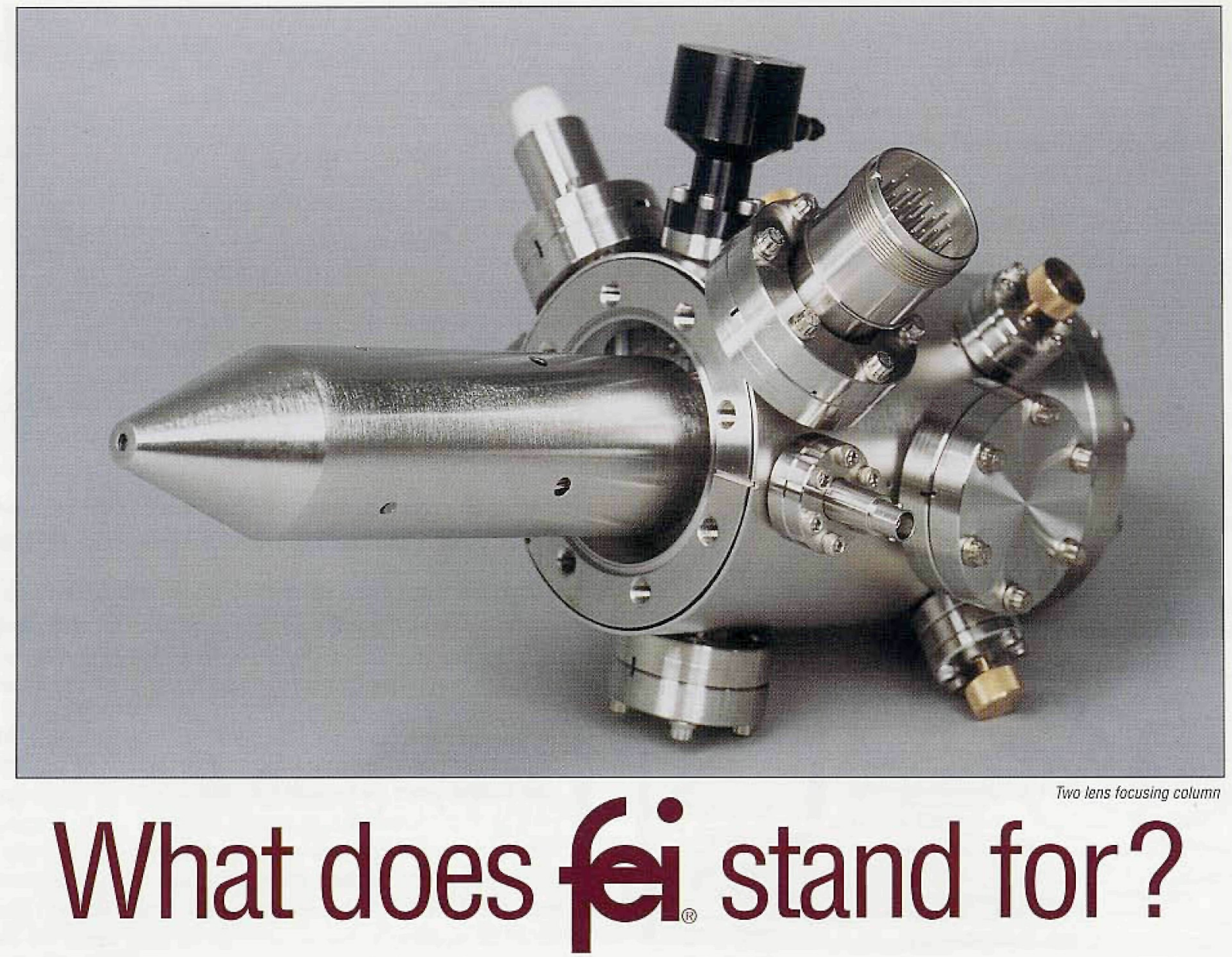

Our compact, UHV, field emission columns are used by researchers world wide. Innovative electrostatic optics and dedicated electronics allow you to integrate a high current density electron or ion column into most vacuum systems. FEl also supplies researchers with other specialized products...

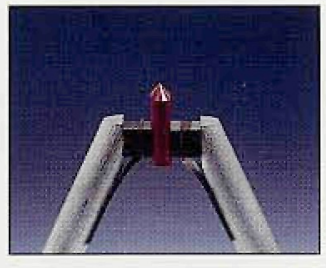

\section{$\mathrm{LaB}_{6}$ an $\mathrm{CeB} 6$ Cathodes}

FEl's Mini-Vogel Mount, the first universally compatible long-life, high-stability LaB6 cathode, provides excellent performance and the best cost-per-use value for installation into your EM systems.

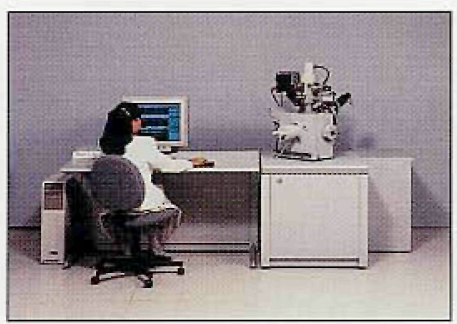

\section{FIB Workstations}

Focused ion beam micromilling workstations range from the 8"-wafer compatible model to the economical 2 " small sample model ideal for semiconductor, biological, TEM, and MEMS specimens.

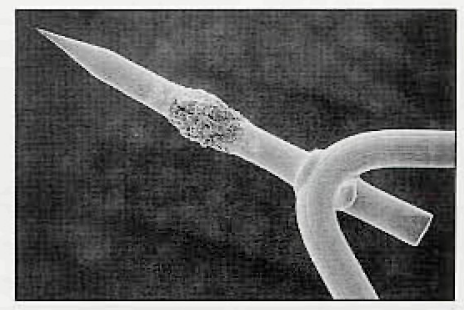

Field Emission Cathodes

FEl supplies Schottky field emitters to EM manufacturers worldwide. Schottky emission's high current intensity has established it as the preferred electron source for high resolution SEM, TEM, Auger, ESCA, EDX, and lithography.

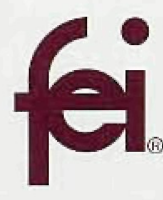

FEI Company

7451 NE Evergreen Parkway

Hillsboro, OR 97124-5830

(503) 640-7500 Fax (503) 640-7509

email:rsk@feico.com

Now, when you think of FEl, you'll know we are the Specialists in Field Electron and Ion Technology. 